\title{
ESTUDO DA IMPORTÂNCIA DO EMPREENDEDORISMO E DA SUA EXISTÊNCIA DENTRO DA CONSCIÊNCIA DE DISCENTES DA UNIVERSIDADE PAULISTA DE ARAÇATUBA/SP
}

\author{
${ }^{1}$ Tiago Aparecido de Oliveira; ${ }^{2}$ Mariane Regina Lorencetti; ${ }^{3}$ Ródney Silvério Costa Junior; ${ }^{4}$ Rafael \\ Marçal \\ ${ }^{1}$ Universidade Paulista UNIP, Campus Araçatuba, SP. e-mail: tiagoengenharia52@gmail.com \\ "Universidade Estadual Paulista "Júlio de Mesquita Filho", Campus Ilha Solteira, SP. \\ "UniSALESIANO Centro Universitário Católico Salesiano Auxilium, Campus Araçatuba, SP. \\ ${ }^{4}$ Universidade Paulista UNIP, Prof. Mestre no curso de Engenharia Civil, Campus Araçatuba, SP.
}

\section{RESUMO}

A cultura empreendedora traz desenvolvimento econômico aos países, pois gera altas taxas de criação de novas empresas e inovações, causando grandes mudanças social e economicamente. Este artigo tem como objetivo coletar dados através de diálogos e questionamentos feitos pessoalmente na Universidade Paulista (UNIP) de Araçatuba- SP, com acadêmicos dos cursos de engenharia civil, engenharia mecânica e arquitetura, discutindo sobre a existência do pensamento empreendedor dos discentes e se pretendem empreender após a conclusão do curso, assim como debater sobre a importância da relação empreendedora entre empresas e universidades, integrando o conhecimento teórico com a prática, desenvolvendo competências únicas e diferenciadas, criando assim uma pedagogia empreendedora. Foi constatado que somente $22 \%$ dos entrevistados desejam empreender, estes sendo, em sua maioria, universitários mais velhos. Conclui-se que a falta de vontade em empreender se deu pela situação financeira dos entrevistados e pela falta de experiência.

Palavras-chave: empreendedorismo, pedagogia empreendedora, desenvolvimento econômico, inovação, Universidade Paulista

\section{STUDY OF THE IMPORTANCE OF ENTREPRENEURSHIP AND ITS EXISTENCE WITHIN THE AWARENESS OF STUDENTS OF THE PAULISTA UNIVERSITY FROM ARAÇATUBA/SP}

\begin{abstract}
The entrepreneurial culture brings economic development to the countries, because it generates high rates of creation of new companies and innovations, causing great changes socially and economically. This article aims to collect data through dialogues and questionings made personally at the Paulista University of Araçatuba- SP, with academics from the civil engineering, mechanical engineering and architecture courses and if they intend to undertake after the conclusion of the course, as well as discussing the importance of the entrepreneurial relationship between companies and universities, integrating theoretical knowledge with practice, developing unique and differentiated skills, thus creating an entrepreneurial pedagogy. It was found that only $22 \%$ of respondents wish to undertake, most of them are older students. It is concluded that the lack of willingness to undertake was due to the financial situation of the interviewees and lack of experience.
\end{abstract}

Keywords: entrepreneurship, entrepreneurial pedagogy, economic development, innovation, Paulista University 


\section{INTRODUÇÃO}

Para que o profissional tenha destaque no mercado de trabalho, é necessário buscar o perfil empreendedor, superando seus limites e dificuldades, trazendo inovações e ideias que mostram diferença ao gerenciar ou participar de uma organização. O empreendedor deve acreditar num determinado projeto buscando o êxito do mesmo não importando as circunstâncias. O empreendedorismo dado a sua força e crescimento, é um fenômeno global nas relações internacionais e formação profissional.

O empreendedorismo é, portanto, um processo humano criativo que mobiliza recursos de um nível de produtividade inferior para outro superior, ou seja, provoca mudanças com impactos de crescimento e desenvolvimento. Isso implica na vontade do indivíduo de assumir responsabilidades e a habilidade de realizar inovações. Outra característica do empreendedorismo consiste em identificar oportunidades onde outras pessoas acham apenas caos, contradições ou confusão. O empreendedorismo consiste em caminhar contra o tempo com sabedoria e maturidade, servindo como agente de mudança. (TOMA; GRIGORE; MARINESCU, 2014).

De acordo com Bispo et. al. (2012), devido a mudanças ocorridas na área econômica houve alterações na definição do empreendedor. Desde os tempos antigos da idade média, todo indivíduo que participava ou administrava grandes projetos de produção era chamado de empreendedor, porém este empreendedor utilizava dos meios e recursos fornecidos pelo governo do país. Com o passar dos anos, esta definição foi se adequando para atender uma nova estrutura econômica, definindo o empreendedorismo com o ato de inovar.

A ideia de inovação é entendida como a criação ou renovação de algo existente, partindo de estudos, observações e persistência, na busca de soluções, buscando o empreendedorismo corporativo (BISPO et. al, 2012).

A função do empreendedor é reformar ou revolucionar o padrão de produção explorando uma invenção ou, de modo geral, um método tecnológico não experimentado para produzir um novo bem ou um bem antigo de maneira nova, abrindo uma nova fonte de suprimento de materiais ou uma nova comercialização para produtos, e organizando um novo setor (SCHUMPETER, 1952, p.72).

A cultura empreendedora traz prosperidade econômica ao país, pois gera altas taxas de criação de novas empresas, consequentemente é criado um cenário de concorrência entre as empresas, e essa concorrência promove uma constante busca pela maior e melhor qualidade e custo possível dos produtos, ocorrendo um processo de alto desenvolvimento econômico. Hoje em dia, Albert Shapero, Karl Vesper e Robert C. Ronstadt transformaram os conceitos de empreendedorismo.

Em quase todas as definições de empreendedorismo, há um consenso de que estamos falando de uma espécie de comportamento que inclui: (1) tomar iniciativa, (2) organizar e reorganizar mecanismos sociais e econômicos a fim de transformar recursos e situações para proveito prático, (3) aceitar o risco ou o fracasso (SHAPERO, 1975, p. 187).

De acordo com Vesper (1975), um perfil empreendedor é aquele que combina várias coisas como recursos, trabalho, materiais e outros ativos para tornar seu valor maior do que antes; também é aquele que introduz mudanças, inovações e uma nova ordem. Para um psicólogo, a necessidade de obter, experimentar ou conseguir algo, experimentar, impulsiona tal pessoa. Já para homens de negócios, um empreendedor pode ser um aliado, uma fonte de suprimento, um cliente ou alguém que cria capital para outros, assim como encontrar melhores caminhos de usar 
recursos, reduzir desperdício e produzir empregos que outras pessoas ficarão satisfeitos em conseguir.

Os empreendedores não são apenas responsáveis pela criação de novas empresas, mas também por sua liderança e sucesso tecnológico, bem como pela criação de novos empregos. Ou seja, os empresários são motores de crescimento econômico e, diferentes níveis de atividades empreendedoras, acarretam implicações importantes para as disparidades na renda países e regiões (FAGGIO; SILVA, 2014)

Através da educação empreendedora é possível criar um indivíduo para as mais diversas situações, adquirindo habilidades, competências, e condições de assumir riscos conforme explicado por Dolabela, (2003), p. 31:

Educar quer dizer evoluir sem mudar as nossas raízes; pelo contrário, reconhecendo e ampliando as energias que dela emanam. É também despertar a rebeldia, a criatividade, a força da inovação para construir um mundo melhor. Mas é principalmente construir a capacidade de cooperar, de dirigir energias para a construção do coletivo. É substituir a lógica do utilitarismo e do individualismo pela construção do humano, do social, da qualidade de vida para todos. (DOLABELA, 2003, p.31)

A inovação, que é algo totalmente ligado ao empreendedorismo, está longe de ser um fenômeno recente, e é inerente ao desenvolvimento humano. O surgimento de inovações com capacidade para mudar o comportamento das pessoas, os métodos de trabalho e o trabalho caracterizam a história da humanidade (GALINDO; MÉNDEZ, 2014)

No entanto, no Brasil o processo para educação básica direcionando o indivíduo a suportar grandes mudanças, inovar e crescer contempla quatro pilares relacionados por DELORS (2001), os quais são citados a seguir:

a. Aprender a conhecer: Aquisição de um vasto repertório de saberes e o domínio dos próprios instrumentos do conhecimento. Supõem habilidades cognitivas - aprender a aprender. É o eixo da competência cognitiva. Trata-se de preparar o indivíduo para ser um caçador de conhecimentos, ou seja, criar o desejo de educar-se constantemente, cuidando do seu próprio desenvolvimento, do autodidatismo.

b. Aprender a fazer: Aquisição de uma qualificação profissional e competências para enfrentar as variações, as mudanças constantes. É o eixo da competência produtiva. Mais do que desenvolvimento de habilidades voltadas para a qualificação profissional, mas, em sentido ampliado, preparando o indivíduo para enfrentar e superar experiências sociais de maneira efetiva.

c. Aprender a conviver com os outros: Aquisição da aprendizagem progressiva do outro e da interdependência quanto a projetos comuns. Enfrentamento das diversidades e do multiculturalismo. É o eixo da competência relacional. É a relação do indivíduo com os outros e com o meio-ambiente entendida na sua concepção mais ampla. Relaciona-se com a cidadania, com a participação e a democracia.

d. Aprender a ser: Contribuir para o desenvolvimento total da pessoa: espírito e corpo, inteligência, sensibilidade, responsabilidade pessoal, sentido estético. É o eixo da competência pessoal. É a relação do indivíduo consigo mesmo, desenvolvendo e fortalecendo sua identidade, autoestima, autoconceito, autoconfiança, autodeterminação, autocuidado.

Portanto, para despertar o pensamento empreendedor é necessário desenvolver no homem, a iniciativa própria, direcionando o indivíduo desde a educação básica o prazer no empreendedorismo e inovações.

O presente artigo tem como objetivo buscar dados através de diálogos com acadêmicos dos cursos de engenharia civil, engenharia mecânica e arquitetura na Universidade Paulista 
(UNIP), no campus da cidade de Araçatuba, se durante a formação e após a formação do curso os discentes pensam em empreender, criando projetos e negócios próprios. Por fim, se acreditam na importância da aproximação nas relações entre empresas e universidades para amadurecer as ideias relacionadas ao empreendedorismo durante o curso, para após a conclusão criar projetos inovadores, enriquecendo a economia e desenvolvendo competências práticas, as quais só estão disponíveis em ambientes corporativos.

\section{METODOLOGIA}

Elaborou-se diálogo com discentes entre o 5 e o 10 dos cursos de engenharia civil, engenharia mecânica e arquitetura na Universidade Paulista (UNIP) no campus de Araçatuba, referente ao pensamento empreendedor dos alunos. Foi perguntado se pretendiam empreender durante e após a formação acadêmica, por fim foi discutido a importância da ligação entre empresa/universidade para a educação profissional e empreendedora. Os resultados foram analisados através de tabela e gráfico.

\section{RESULTADOS}

Tabela 1. Quantidade de alunos que pretendem/não pretendem empreender

\begin{tabular}{|c|c|c|c|c|c|}
\hline Perguntas & $\begin{array}{c}\text { Engenharia } \\
\text { Civil 5o e 6o } \\
\text { Termo }\end{array}$ & $\begin{array}{c}\text { Engenharia } \\
\text { Civil 7o e 8o } \\
\text { Termo }\end{array}$ & $\begin{array}{l}\text { Engenharia } \\
\text { Civil 9o e 10o } \\
\text { Termo }\end{array}$ & $\begin{array}{l}\text { Engenharia } \\
\text { Mecânica 70 } \\
\text { e 8ㅇ Termo }\end{array}$ & $\begin{array}{c}\text { Arquitetura } \\
\text { 10 e 20 } \\
\text { Termo }\end{array}$ \\
\hline $\begin{array}{l}\text { Quantidade de } \\
\text { alunos que } \\
\text { pretendem } \\
\text { empreender após a } \\
\text { formação } \\
\text { acadêmica }\end{array}$ & 15 & 7 & 10 & 8 & 6 \\
\hline $\begin{array}{l}\text { Quantidade de } \\
\text { alunos que não } \\
\text { pretendem } \\
\text { empreender após a } \\
\text { formação } \\
\text { acadêmica }\end{array}$ & 21 & 33 & 36 & 42 & 41 \\
\hline Total de Alunos & 36 & 40 & 46 & 40 & 47 \\
\hline
\end{tabular}

Fonte: Próprio autor 
Gráfico 1. Porcentagens de alunos que pretendem/não pretendem empreender

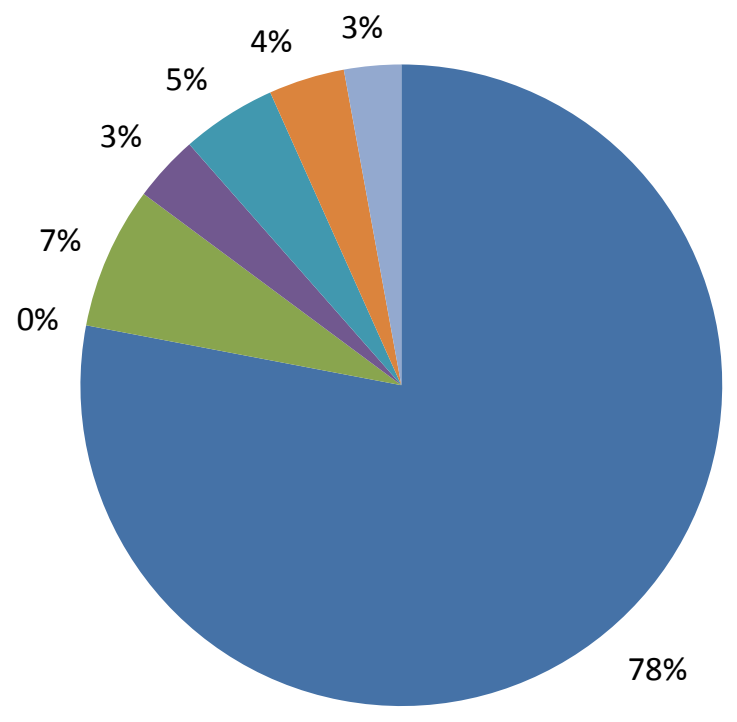

não pretendem empreender

Pretendem empreender de eng. civil 5ㅇ e 6을 termo

- Pretendem empreender de eng. civil $7 \circ \mathrm{E} 8 \stackrel{0}{\circ}$ termo

Pretendem empreender de eng. civil 9o E 10 termo

- Pretendem empreender de eng. mecânica 7으 e 8o termo

- Pretendem empreender de arquitetura 1 으 e 20 termo

Fonte: Próprio autor

\section{DISCUSSÃO}

Como é visto na tabela 1, a sala que mais mostrou o desejo de empreendedorismo foi o 5은 e o 60 de engenharia civil, em que $42 \%$ desejam empreender, e a sala com a menor taxa foi a da arquitetura - 10 e 2 o termo - somente $13 \%$ relataram esse desejo, por estarem no começo do curso, não pensaram ainda sobre o que irão fazer após a conclusão.

De acordo com o gráfico 1, constatou-se que somente $22 \%$ desejam empreender após a formação acadêmica. Os discentes que não pretendem empreender afirmam que é devido à falta de experiência e condições financeiras. A maior escolha vindo dos mais jovens está em se formar, conseguir uma oportunidade de trabalho, se especializar e após todo esse processo, talvez pensar em empreender em sua área de atuação. Em contrapartida, outros discentes, estes sendo os com mais idade, que possuem alguma experiência ou aqueles que no ambiente familiar tem-se o perfil empreendedor ou que algum integrante da família já está ligado ao empreendedorismo, pretendem após sua formação iniciar ou dar segmento a um projeto empreendedor.

A pergunta feita sobre a integração entre universidades e empresas, teve uma grande parte de aprovação, pois alunos concordam que esta integração faz bem para o aprendizado profissional, desde que exista um bom acompanhamento já no primeiro ano do curso.

\section{CONCLUSÃO}

Neste artigo pode-se analisar que sempre existiu o ato de empreender, assim como indivíduos preocupados e com visão de crescimento, inovando e utilizando das situações adversas para crescer economicamente. Também se notou que com a pedagogia empreendedora é possível criar um futuro profissional com competências inovadoras, para que no meio do caos possa enxergar oportunidades, buscando a evolução, desenvolvimento, criatividade e solução de problemas, criando novos produtos, serviços, metodologias com maior qualidade e inovação.

Através dos diálogos elaborados nas salas de engenharia civil, engenharia mecânica e arquitetura verificou-se nos acadêmicos o pensamento empreendedor, porém há a preocupação em relação ao momento correto para empreender dentro das suas carreiras, ou seja, na maioria dos casos, há primeiramente o desejo de adquirir experiência de campo antes de criar um negócio próprio. Portanto, buscam primeiro se especializar, a estabilidade financeira e a experiência profissional, para adquirir visão e competências a fim de empreender de forma segura. 
Nota-se por parte dos acadêmicos a falta de um apoio quanto aos cursos de engenharia e arquitetura, quando se trata de empreender. Sugere-se no início do curso haver um acompanhamento entre empresa e universidade, até mesmo na grade curricular, buscando no aluno o empreendedorismo, conforme DELORS (2001) relatou. Outro fato que impede no Brasil tanto os recém-formados quanto profissionais já com experiência no mercado de trabalho de empreender, é a enorme burocracia e alta tributação existente para uma pessoa que queira abrir sua própria empresa ou negócio. Tal fato desmotiva o empreendedor, ou seja, falta o devido apoio e subsídio para que o brasileiro possa ter condições favoráveis para empreender e progredir social e economicamente.

Por fim, nos levantamentos feitos neste artigo, entende-se que empreender não é somente abrir um próprio negócio, ou seja, uma vez que o profissional ou estudante começa a pensar na sua própria qualificação tanto teórica quanto prática, deseja desenvolver competências dentro de ambientes corporativos e visões críticas diferenciadas sobre o mercado, buscando inovação, resolução de problemas e otimização de processos produtivos, esta pessoa já está empreendendo. Empreender é inovar, alavancar mudanças e gerar impactos positivos no meio em que vive e trabalha, ou seja, quebrar paradigmas sociais, econômicos e profissionais.

\section{REFERÊNCIAS}

DELORS, J.. Educação: um tesouro a descobrir. 8. Ed. São Paulo: Cortez Brasília, DF: MEC/UNESCO, 2001.

DOLABELA, F.. Pedagogia Empreendedora. São Paulo: Editora de Cultura, 2003.

ENDEAVOR BRASIL. O que é empreendedorismo: da inspiração à prática.Disponível em: https://endeavor.org.br/tudo-sobre/empreendedorismo/. Acesso em: 13 ago. 2017.

RONSTADT, R.. Entrepreneuship: text, cases and notes. [S.L.]: Lord Pub, 1984. p.28.

SCHUMPETER, J.. Can capitalism survive? New York: Harper \& Row, 1952. p.72.

SHAPERO, A.. Entrepreneurship and economic development. [S.L.: s.n.], 1975. p.187.

TOMA, S. G.; GRIGORE, A. M.; MARINESCU, P. Economic Development and Entrepreneurship. v. 8 [S.L.]: Elsevier,2014. p.436-443.

FAGGIO, G.; SILVA, O.. Self-employment and entrepreneurship in urban and rural labour markets. Journal Of Urban Economics, [s.I.], v. 84, p.67-85, nov. 2014. Elsevier BV. http://dx.doi.org/10.1016/i.jue.2014.09.001.

GALINDO, M.-Á.; MÉNDEZ, M. T.. Entrepreneurship, economic growth, and innovation: Are feedback effects at work?. Journal Of Business Research, [s.I.], v. 67, n. 5, p.825-829, maio 2014. Elsevier BV. http://dx.doi.org/10.1016/i.jbusres.2013.11.052.

BISPO, C. dos S. et al. Empreendedorismo e Inovação. 2012. Disponível em: >http://www.ibes.edu.br/aluno/arquivos_empreendedorismo_inovação.pdf> Acesso em 9 ago. 2017. 